\title{
FRACTAL CHARACTERIZATION OF TIGHT OIL RESERVOIR PORE STRUCTURE USING NUCLEAR MAGNETIC RESONANCE AND MERCURY INTRUSION POROSIMETRY
}

\author{
FUYONG WANG* and KUN YANG \\ Research Institute of Enhanced Oil Recovery \\ China University of Petroleum (Beijing), No. 18, Fuxue Road \\ Beijing 102249, P. R. China \\ *wangfuyong@cup.edu.cn \\ JIANCHAO CAI \\ Shandong Provincial Key Laboratory of \\ Depositional Mineralization \& Sedimentary Minerals \\ Shandong University of Science and Technology \\ Qingdao 266590, P.R. China \\ Hubei Subsurface Multi-Scale Imaging Key Laboratory \\ Institute of Geophysics and Geomatics \\ China University of Geosciences \\ Wuhan 430074, P. R. China \\ Received January 17, 2018 \\ Accepted February 18, 2018 \\ Published March 20, 2018
}

\begin{abstract}
Tight oil sandstones have the characteristics of narrow pore throats, complex pore structures and strong heterogeneities. Using nuclear magnetic resonance (NMR) and mercury intrusion porosimetry (MIP), this paper presents an advanced fractal analysis of the pore structures and petrophysical properties of the tight oil sandstones from Yanchang Formation, Ordos Basin of China. Firstly, nine typical tight oil sandstone core samples were selected to conduct NMR and MIP test for pore structure characterization. Next, with the pore size distribution derived
\end{abstract}

\footnotetext{
${ }^{*}$ Corresponding author.

This is an Open Access article published by World Scientific Publishing Company. It is distributed under the terms of the Creative Commons Attribution 4.0 (CC-BY) License. Further distribution of this work is permitted, provided the original work is properly cited.
} 
from MIP, it was found that the relationships between NMR transverse relaxation time $T_{2}$ and pore size are more accordant with the power function relations, which were applied to derive pore size distribution from NMR rather than the linear relation. Moreover, fractal dimensions of micropores, mesopores and macropores were calculated from NMR $T_{2}$ spectrum. Finally, the relationships between the fractal dimensions of different size pores calculated from NMR $T_{2}$ spectrum and petrophysical properties of tight oil sandstones were analyzed. These studies demonstrate that the combination of NMR and MIP can improve the accuracy of pore structure characterization and fractal dimensions calculated from NMR $T_{2}$ spectrum are effective for petrophysical properties analysis.

Keywords: Nuclear Magnetic Resonance (NMR); Mercury Intrusion Porosimetry (MIP); Tight Oil; Sandstone; Pore Structure; Fractal Dimension.

\section{INTRODUCTION}

Tight oil is a kind of unconventional resources and attracts more and more attentions in recent years. ${ }^{112}$ Effectively exploiting tight oil resources is challenging due to the ultra-low permeability. Pore structures of tight formations are intrinsic factors affecting the storage and development of tight oil reservoirs. The tight oil reservoirs are characterized by small pore throat radius, high capillary pressure, high original water saturation, complex pore structure and strong heterogeneities ${ }^{3 / 4}$ Characterization of tight oil reservoir pore structures is of great significance for developing tight oil reservoirs.

Since fractal geometry theory was proposed by Mandelbrot in $1970 \mathrm{~s}, \frac{5}{5}$ it has been widely used in many fields such as mathematics, physics, materials and geology. In petroleum geology, fractal theory has been widely used for pore structure characterization and fluid flow modeling in porous media of sedimentary rock due to the self-similarity characteristics of pore volume distribution, pore size and pore throat structures ${ }^{6}-8$ For instance, Wang et al. applied the fractal theory to characterize the complex and irregular pore throat structure of carbonates. ${ }^{9}$ Cai et al. utilized the fractal dimension to quantify complexity of the dynamic fractured network which is significant for evaluating of hydraulic fracturing operation in unconventional reservoirs. 10

At present, the test methods for pore structure characterization with fractal theory include mercury intrusion porosimetry (MIP) 11112 ning electron microscope (SEM) ${ }^{13} \mathrm{CT}$ scanning, 14 nuclear magnetic resonance (NMR), 15 nitrogen adsorption, $\frac{16}{16}$ etc. Among them, NMR utilizes the spin motion of the nucleus to obtain the information of internal microstructure and fluid flow state. Because of its advantages of short measurement time and no damage to samples, NMR has been widely used for analyzing pore structures and fluid state in porous media. In 1990s, NMR began to be applied to study the pore characteristics of sedimentary rock.17 With the development of unconventional oil and gas, NMR is gradually applied to the study of the pore characteristics of unconventional reservoirs. 18 Yao et al. applied the NMR to study the pore characteristics of coals and the strong correlation between transverse relaxation time $T_{2}$ and pore structures of coals were

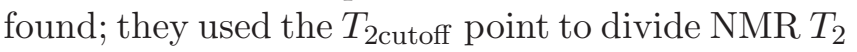
spectrum and pore distribution models were established combining with MIP.21 They also compared MIP, constant-rate-controlled mercury porosimetry, micro-CT and NMR for analyzing pore size distribution and found that NMR can better evaluate pore size distribution of coal under nondestructive conditions $\stackrel{22}{22}_{\text {Ge et }}$ al. analyzed the multifractal characteristics of sandstone pore space using NMR technology and the $T_{2 \text { cutoff }}$ value was predicted based on multifractal thoery 23 Zhao et al. investigated the pore structures of artificial cores with micro-CT and NMR, and they found that compared with micro-CT, NMR is better to describe the fractal characteristics of pore pace with wide pore size range.15 Zhang et al. compared the fractal dimensions calculated from NMR $T_{2}$ spectrum with the fractal analysis results derived from MIP and $\mathrm{N}_{2}$ adsorption, and found that the fractal dimensions calculated from longer NMR transverse relaxation time and shorter NMR transverse relaxation time, respectively, reflect the volume dimension and surface dimension of pores. 24

This paper presents the fractal characterization of tight oil sandstone pore structures using NMR and MIP. The relations between NMR transverse relaxation time $T_{2}$ and pore size were investigated, and the fractal dimensions of micropores, mesopores 
and macropores were calculated from NMR $T_{2}$ spectrum. Finally, the relationships between the fractal dimensions of different size pores calculated from NMR $T_{2}$ spectrum and tight oil sandstone petrophysical properties were analyzed.

\section{EXPERIMENTS}

\subsection{Core Samples}

Nine natural core samples of tight oil sandstones collected from Yanchang Formation, Ordos Basin of China were selected for NMR and MIP tests. The parameters of core samples were shown in Table 1. These core samples were from different layers. The core sample 1 was collected from Chang 6, and the core samples $2-3$ were collected from Chang 8 , and the core samples 4-9 were collected from the Chang $4+5$. All the data related to the core samples 4-9 were originally from Chang. ${ }^{25]}$ The tightest core sample is the core sample 1 , and its porosity is only $4.54 \%$ with $0.0437 \mathrm{mD}$ air permeability. The porosity of the core sample 2 is $10.81 \%$, but the air permeability is only $0.382 \mathrm{mD}$. Although the porosity of core sample $3-7$ is more than $15 \%$, the core permeability is very low, varying from $0.315 \mathrm{mD}$ to $3.43 \mathrm{mD}$. Therefore, these tight sandstones present the characteristics of high porosity and low permeability. NMR and MIP tests were conducted to investigate the pore throat structures of these core samples.

\subsection{Nuclear Magnetic Resonance}

As a non-destructive method of pore structure analysis, NMR experiments were conducted before MIP. Firstly, clean and dry core samples. Then, the core samples were vacuumed and saturated with formation water. After that, NMR $T_{2}$ spectrum of each core sample was measured using the Oxford NMR instrument under $35^{\circ} \mathrm{C}$. During the NMR measurement, $0.3 \mathrm{~ms}$ echo interval was adopted, and core samples were scanned with 64 times and 2048 echoes were obtained. NMR $T_{2}$ spectrum of each core sample saturated with formation water is shown in Fig. 1.

As an important parameter in NMR logging data, $T_{2 \text { cutoff }}$ can divide the fluid in the pore space into two parts. The fluid with transverse relaxation time

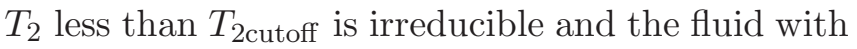
transverse relaxation time $T_{2}$ greater than $T_{2 \text { cutoff }}$ is free. ${ }^{26}$ The $T_{2 \text { cutoff value can be determined from }}$ the cumulative porosity of NMR $T_{2}$ spectrum under different water saturation. URC-628 instrument was used to centrifuge the $100 \%$ saturated core samples under 200 psi. After the centrifuge, the NMR $T_{2}$ spectrum of each core sample under irreducible water saturation was measured, as shown in Fig. 2 .

\subsection{Mercury Intrusion Porosimetry}

MIP is a conventional method for pore structure analysis and widely used to obtain the pore size distribution of core samples. Mercury is a non-wet phase and with the injected pressure greater than the capillary pressure, mercury enters the connected pores and mercury saturation increases. With continually increasing injected pressure, mercury saturation under different capillary pressure can be obtained. As the mercury pressure is responding to pore size, pore size distribution and pore structure parameters can be derived from MIP experiment. The relationship between capillary pressure $P_{c}$ and pore radius $r$ can be described with Washburn Equation 27 .

$$
P_{c}=\frac{2 \sigma \cos \theta}{r},
$$

Table 1 The Porosity, Permeability and Pore Structure Parameters of Core Samples.

\begin{tabular}{|c|c|c|c|c|c|c|c|}
\hline Sample & $\begin{array}{c}\text { Porosity } \\
\phi(\%)\end{array}$ & $\begin{array}{c}\text { Air } \\
\text { Permeability } \\
K_{\text {air }}(\mathrm{mD})\end{array}$ & $\begin{array}{c}\text { Displacement } \\
\text { Pressure } \\
P_{\text {cd }}(\mathrm{MPa})\end{array}$ & $\begin{array}{c}\text { Maximum Pore } \\
\text { Throat Radius } \\
r_{\max }(\mu \mathrm{m})\end{array}$ & $\begin{array}{c}\text { Median Pore } \\
\text { Radius } \\
r_{50}(\mu \mathrm{m})\end{array}$ & $\begin{array}{c}\text { Tortuosity } \\
\tau\end{array}$ & $\begin{array}{c}\text { Sorting } \\
\text { Coefficient } \\
S_{p}\end{array}$ \\
\hline 1 & 4.54 & 0.0437 & 2.743 & 0.268 & 0.043 & 7.57 & 1.927 \\
\hline 2 & 10.81 & 0.382 & 0.464 & 1.583 & 0.293 & 2.12 & 2.819 \\
\hline 3 & 15.28 & 1.86 & 0.263 & 2.79 & 0.399 & 2.91 & 2.912 \\
\hline 4 & 15.41 & 0.315 & 0.468 & 1.572 & 0.093 & 4.36 & 3.02 \\
\hline 5 & 15.56 & 0.834 & 0.676 & 1.088 & 0.158 & 3.22 & 2.983 \\
\hline 6 & 17.2 & 0.96 & 2.054 & 0.358 & 0.051 & 2.69 & 2.474 \\
\hline 7 & 15.65 & 1.71 & 0.195 & 3.769 & 0.304 & 1.96 & 2.883 \\
\hline 8 & 17.02 & 2.018 & 0.332 & 2.214 & 0.34 & 2.49 & 2.855 \\
\hline 9 & 17.46 & 3.43 & 0.194 & 3.786 & 0.359 & 1.47 & 3.101 \\
\hline
\end{tabular}




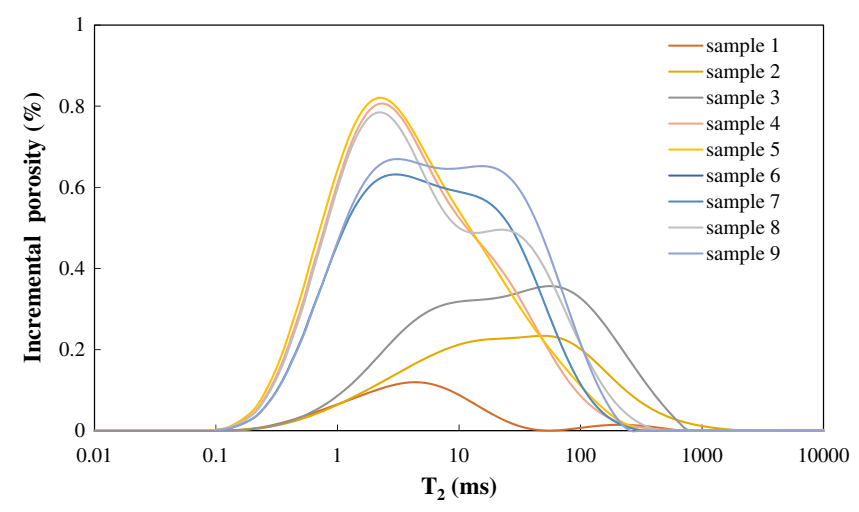

Fig. 1 NMR $T_{2}$ spectrum of each core sample under $100 \%$ water saturation.

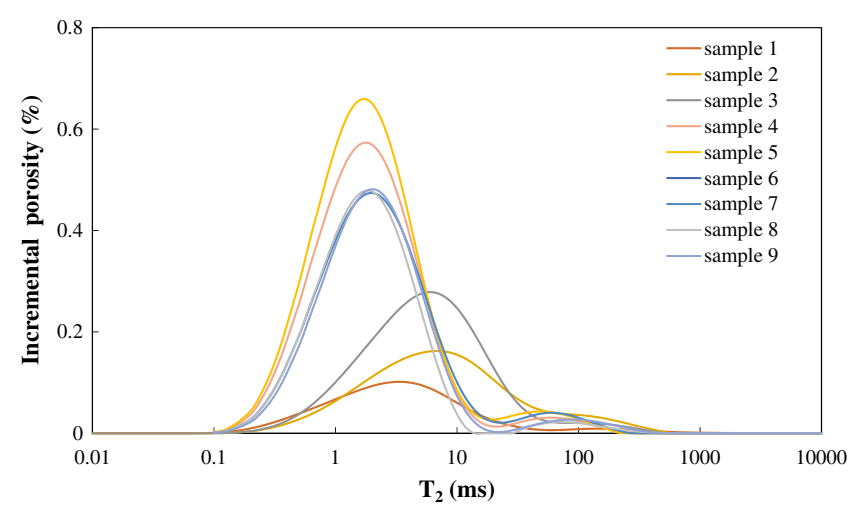

Fig. 2 NMR $T_{2}$ spectrum of each core sample under irreducible water saturation after centrifugation.

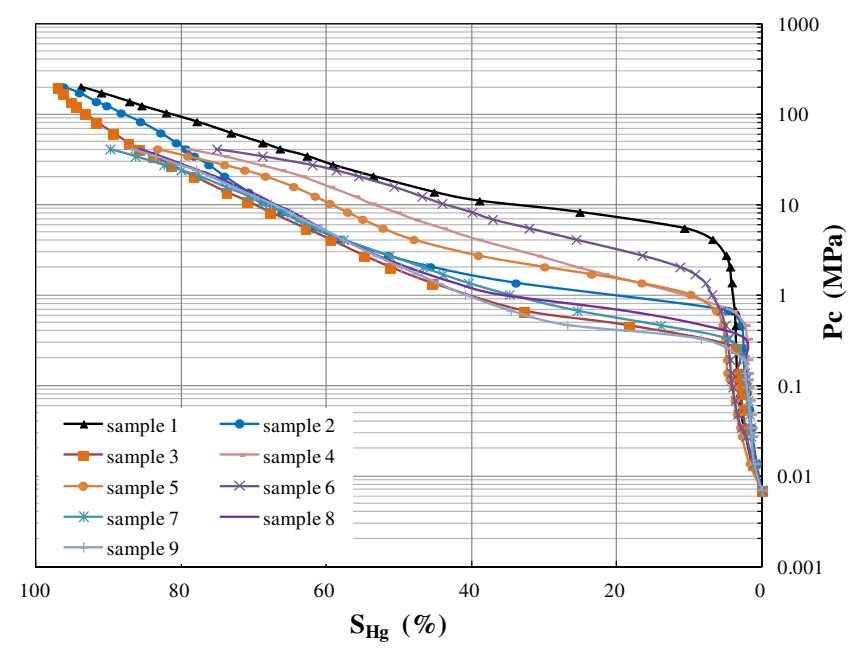

Fig. 3 The mercury capillary pressure curves of all core samples.

where $\sigma$ is the surface tension between mercury and air, and $\theta$ is the contact angle between mercury and rock. Figure 3 shows the mercury capillary pressure curves of all core samples, and the pore structure parameters derived from MIP are shown in Table 1 .
MIP test demonstrated that the tiny pore throat size accounts for the ultra-low permeability of core samples. For instance, the maximum pore throat size $r_{\max }$ and median pore throat size $r_{50}$ of the core sample 1 are only $0.268 \mu \mathrm{m}$ and $0.043 \mu \mathrm{m}$, respectively, and are much smaller than those of other core samples, which can explain that the air permeability of core sample 1 is the lowest in all core samples. Compared with core samples 3 and 4 , although the porosity of core sample 4 is a little larger than that of core sample 3 , the air permeability of core sample 3 is nearly one order of magnitude greater than that of core sample 4 , and the reason can be inferred from the pore size distribution of these two core samples. The maximum pore throat size $r_{\max }$ of core sample 3 is nearly twice that of core sample 4 , and the median pore throat size $r_{50}$ of core sample 3 is nearly three times greater than that of core sample 4.

\section{METHODOLOGY DESCRIPTION}

The total transverse relaxation time of NMR is superimposed by several mechanisms ${ }^{28}$ :

$$
\frac{1}{T_{2}}=\frac{1}{T_{2 B}}+\rho\left(\frac{S}{V}\right)+\frac{D\left(\gamma G T_{E}\right)^{2}}{12},
$$

where $T_{2}$ is the transverse relaxation time, ms; $\frac{1}{T_{2 B}}$ is the transverse volume relaxation, and $T_{2 B}$ is the transverse volume transverse relaxation time, ms; $\rho\left(\frac{S}{V}\right)$ is the transverse surface relaxation; $\rho$ is the transverse surface relaxation strength, $\mu \mathrm{m} / \mathrm{ms} ; S$ is the superficial area of pore, $\mu \mathrm{m}^{2} ; V$ is the pore volume, $\mu \mathrm{m}^{3} ; \frac{D\left(\gamma G T_{E}\right)^{2}}{12}$ is the transverse diffusion relaxation; $D$ is the diffusion coefficient, $\mu \mathrm{m}^{2} / \mathrm{ms}$; $G$ is the average gradient of magnetic field, $10^{-4}$ $\mathrm{T} / \mathrm{cm} ; T_{E}$ is the echo interval, $\mathrm{ms} ; \gamma$ is gyromagnetic ratio, $(\mathrm{T} \cdot \mathrm{ms})^{-1}$.

When there is only one type of fluid in the rock with uniform magnetic field, and the echo interval is short enough, the transverse volume relaxation $\frac{1}{T_{2 B}}$ and diffusion relaxation $\frac{D\left(\gamma G T_{E}\right)^{2}}{12}$ can be ignored. Therefore, the Eq. (1) can be simplified as 59

$$
\frac{1}{T_{2}}=\rho\left(\frac{S}{V}\right)=F_{S} \frac{\rho}{r}
$$

where $r$ is the pore throat radius and $F_{S}$ is the form factor; for cylinder pores, $F_{S}=2$, and for spherical pores, $F_{S}=3$. 
Rearrange Eq. (3), and $T_{2}$ can be expressed as

$$
T_{2}=\frac{r}{F_{S} \rho} \text {. }
$$

According to fractal geometry theory, the cumulative pore volume fraction $S_{V}$ can be expressed as

$$
S_{V}=\frac{V(<r)}{V_{s}}=\frac{r^{3-D_{f}}-r_{\min }^{3-D_{f}}}{r_{\max }^{3-D_{f}}-r_{\min }^{3-D_{f}}},
$$

where $D_{f}$ represents the fractal dimension of pore space in three-dimensional space. When $r_{\min } \ll$ $r_{\max }$, Eq. (5) can be simplified as

$$
S_{V}=\frac{r^{3-D_{f}}}{r_{\max }^{3-D_{f}}} .
$$

Submitting Eq. (4) into Eq. (6),

$$
S_{V}=\left(\frac{T_{2 \max }}{T_{2}}\right)^{\left(D_{f}-3\right)} .
$$

Applying logarithm operation on both sides of Eq. (77), it can be expressed as

$$
\lg S_{V}=\left(3-D_{f}\right) \lg T_{2}+\left(D_{f}-3\right) \lg T_{2 \max },
$$

where $S_{V}$ is the cumulative pore volume fraction when the transverse relaxation time is less than $T_{2}$, and $T_{2 \max }$ is the maximal transverse relaxation time. By plotting $S_{V}$ and the corresponding $T_{2}$ in a $\log -\log$ plot, the fractal dimension $D_{f}$ can be calculated from the slope of the $\lg S_{V}-\lg T$ curve. Assuming that the slope is $S$, the fractal dimension $D_{f}$ can be calculated by $D_{f}=3-S$.

For the method stated above, it is assumed that transverse relaxation time $T_{2}$ is linearly correlated with pore radius. However, many studies indicate that there is a power function relation between transverse relaxation time $T_{2}$ and pore radius $30-32$.

$$
T_{2}=\frac{r^{n}}{F_{s} \rho}
$$

where $n$ is the exponent. Core sample 3 was taken as an example to investigate the relationship between transverse relaxation time $T_{2}$ and pore radius. Firstly, the cumulative pore volume fraction curves of NMR and MIP were plotted in the same figure, as shown in Fig. 4. For the same cumulative pore volume fraction, the corresponding transverse relaxation time $T_{2}$ and pore radius can be determined. Linear regression and power regression were, respectively, utilized to fit the relation between transverse relaxation time $T_{2}$ and pore radius, as shown in Fig. 5. The determination coefficient of power regression result is higher than that of linear regression. Table 2 shows the regression results

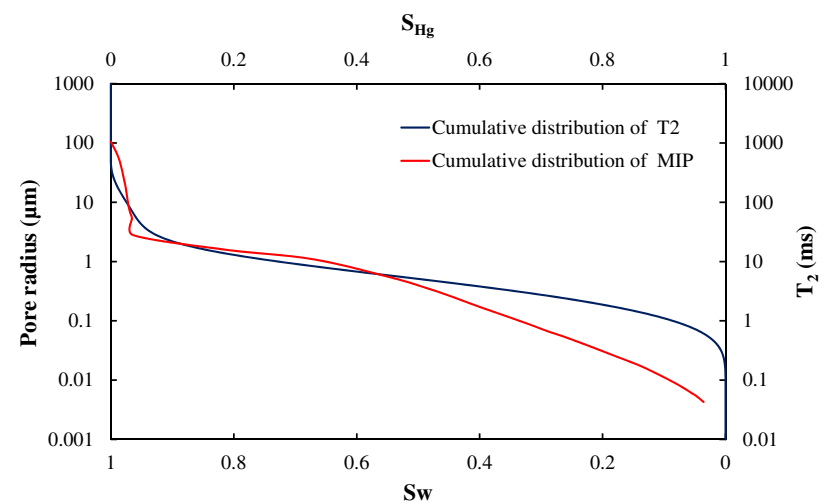

Fig. 4 Cumulative pore volume fraction of NMR and MIP under water/mercury saturation.

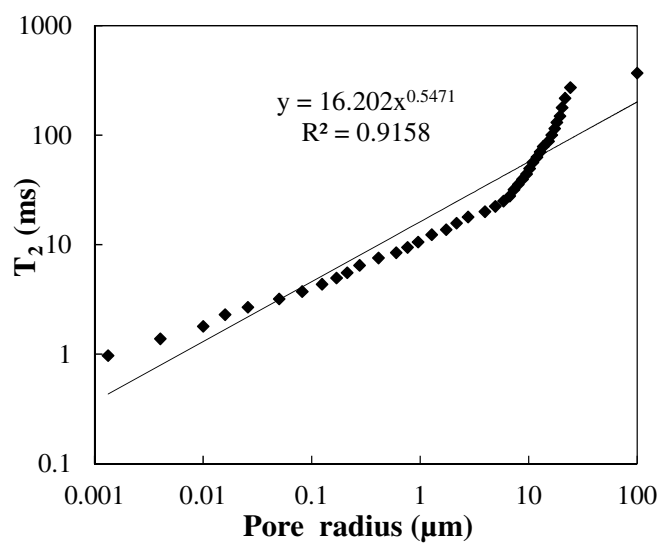

(a)

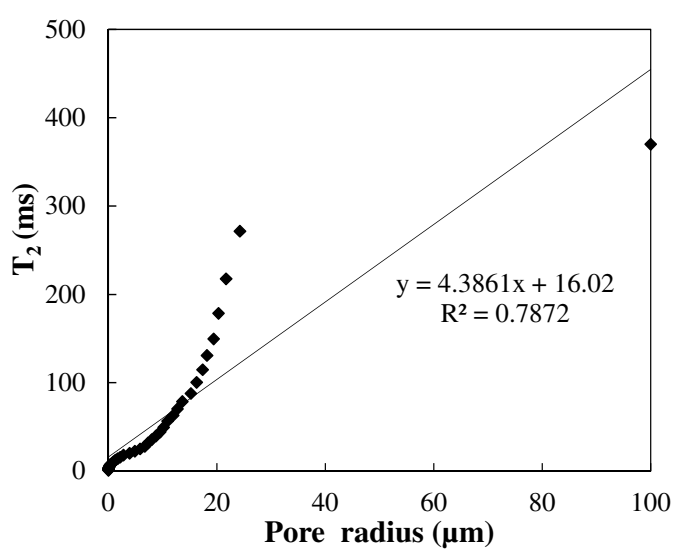

(b)

Fig. 5 Regression results of the relationship between $T_{2}$ and pore radius ((a) using power regression; (b) using linear regression).

of all the core samples using these two different regression methods. The results of power regression are much better than the linear regression results, which means that the relationship between transverse relaxation time $T_{2}$ and pore radius is closer to power function relation. 
Table 2 The Regression Results of $T_{2}$ and Pore Radius Relationship Using Power Regression and Linear Regression for All the Core Samples.

\begin{tabular}{cccccc}
\hline \multirow{2}{*}{ Sample } & \multicolumn{2}{c}{ Power Regression } & & \multicolumn{2}{c}{ Linear Regression } \\
\cline { 2 - 3 } \cline { 5 - 6 } & $\begin{array}{c}\text { Regression } \\
\text { Formula }\end{array}$ & $\begin{array}{c}\text { Determination } \\
\text { Coefficient } \boldsymbol{R}^{2}\end{array}$ & & $\begin{array}{c}\text { Regression } \\
\text { Formula }\end{array}$ & $\begin{array}{c}\text { Determination } \\
\text { Coefficient } \boldsymbol{R}^{2}\end{array}$ \\
\hline \multirow{2}{*}{1} & $y=13.427 x^{0.5227}$ & 0.9022 & & $y=0.3696 x-2.5779$ & 0.9021 \\
2 & $y=22.254 x^{0.5268}$ & 0.8591 & & $y=7.2916 x+22.225$ & 0.8178 \\
3 & $y=16.202 x^{0.5471}$ & 0.9158 & & $y=4.3861 x+16.020$ & 0.7872 \\
4 & $y=20.693 x^{0.7971}$ & 0.9433 & & $y=3.0919 x+8.5355$ & 0.8634 \\
5 & $y=5.5145 x^{0.8983}$ & 0.9434 & & $y=4.4683 x-2.8234$ & 0.7778 \\
6 & $y=16.612 x^{0.8098}$ & 0.8894 & & $y=2.5002 x+14.248$ & 0.6618 \\
7 & $y=20.622 x^{0.7884}$ & 0.9573 & & $y=0.032 x+0.0835$ & 0.9316 \\
8 & $y=16.723 x^{0.7222}$ & 0.9185 & & $y=6.6008 x+2.6833$ & 0.7139 \\
9 & $y=16.125 x^{0.6676}$ & 0.9445 & $y=1.9412 x+14.599$ & 0.6025 \\
\hline
\end{tabular}

Submitting Eq. (9) into Eq. (6)),

$$
S_{V}=\left(\frac{T_{2 \max }}{T_{2}}\right)^{\frac{\left(D_{f}-3\right)}{n}} .
$$

Applying logarithm operation on both sides of Eq. (10), it can be expressed as

$$
\lg S_{V}=\frac{\left(3-D_{f}\right)}{n} \lg T_{2}+\frac{\left(D_{f}-3\right)}{n} \lg T_{2 \max } .
$$

As Eq. (11) shows, the fractal dimensions corrected with the power function relation between $T_{2}$ and pore size can be calculated from the slope of $\lg S_{V^{-}}$ $\lg T_{2}$ curve by $D_{f}=3-n S$.

\section{FRACTAL ANALYSIS OF PORE STRUCTURES WITH NMR}

The NMR $T_{2}$ spectrum contains the transverse relaxation time of different size pores. However, the fractal characteristics of macropores are quite different from those of micropores, and analyzing the structures of different size pores using one fractal dimension may not be reasonable. Therefore, the entire NMR $T_{2}$ spectrum should be divided into several segments to analyze fractal characteristics of different size pores.

\subsection{NMR $T_{2}$ Spectrum Segmentation}

Based on the value of $T_{2 \text { cutoff }}$, the entire NMR $T_{2}$ spectrum was divided into three segments, which represent the NMR responses of micropores, mesopores and macropores. In this paper, the initial transverse relaxation time $T_{2}$ for micropores is noted as $T_{2 i}$; the split points to separate the $T_{2}$ spectrum of mesopores from micropores and macropores are noted as $T_{2 a}$ and $T_{2 b}$; the end transverse relaxation time $T_{2}$ for macropores is noted as $T_{2 n}$. Thus, the ranges of NMR $T_{2}$ spectrum for micropores, mesopores and macropores can be expressed as $T_{2 i}-T_{2 a}, T_{2 a}-T_{2 b}$ and $T_{2 b}-T_{2 n}$, respectively. As the interval time of NMR echo in the NMR experiments is $0.3 \mathrm{~ms}$, the initial transverse relaxation time $T_{2}$ for the micropores $T_{2 i}$ equals $0.3 \mathrm{~ms}$. It is well known that $T_{2 \text { cutoff }}$ can divide NMR $T_{2}$ spectrum into two parts - irreducible fluids and free fluids. As the irreducible fluids are mainly distributed in micropores, $T_{2 \text { cutoff }}$ was used as the split point to separate micropores and mesopores, i.e., $T_{2 a}=T_{2 \text { cutoff. }}$ Thus, the range of $T_{2}$ spectrum for micropores is from $0.3 \mathrm{~ms}$ to $T_{2 \text { cutoff }}$. To separate mesopores from macropores on NMR $T_{2}$ spectrum, this paper used the value of $9 T_{2 \text { cutoff }}$ as the $T_{2 b}$, i.e., $T_{2 b}=9 T_{2 \text { cutoff }}$. One of the reasons is that $T_{2 b} / T_{2 \text { cutoff }}=9$ can ensure that the assumption of $r_{\min } \ll r_{\max }$ is valid, 24 and previous studies also found that using $9 T_{2 \text { cutoff }}$ as the split point can ensure the linear regressions of $\lg S_{V}$ and $\lg T_{2}$ for mesopores and macropores which are both satisfying. ${ }^{[15]}$ Thus, the range of $T_{2}$ spectrum for mesopores is from $T_{2 \text { cutoff to }} 9 T_{2 \text { cutoff }}$. When $T_{2}$ increases to a certain value, the cumulative porosity becomes constant and equals to 1 , and this certain value of $T_{2}$ is the ending point of $T_{2}$ spectrum for macropores $T_{2 n}$.

Taken core sample 3 as an example, Fig. 6 shows how the $T_{2 \text { cutoff }}$ and split points in $T_{2}$ spectrum were determined. The cumulative porosity curves under $100 \%$ water saturation and irreducible water saturation were plotted in the same figure. After centrifugal with 200 psi, the cumulative absolute porosity 


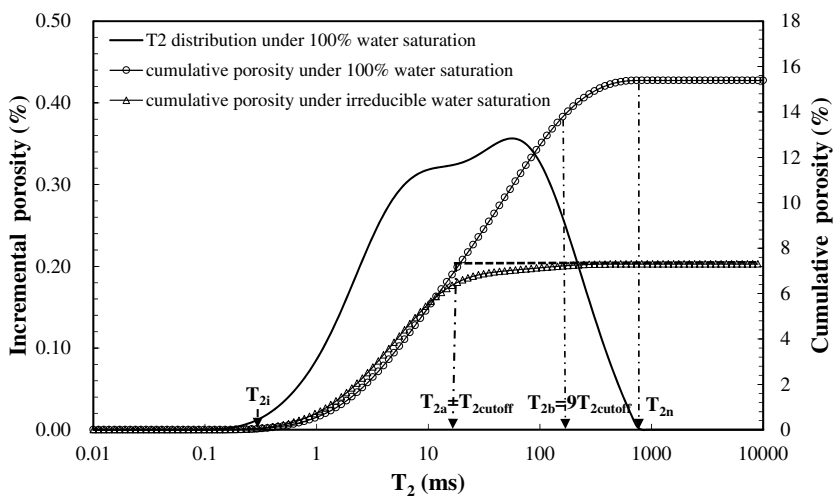

Fig. 6 The determination of $T_{2 \text { cutoff }}$ and split pionts on NMR $T_{2}$ spectrum.

of water was reduced from $15.384 \%$ to $7.299 \%$. A horizontal projection was drawn from the cumulative porosity under irreducible water saturation, and the intersection of the horizontal line and the cumulative porosity under $100 \%$ water saturation can give the value of $T_{2 \text { cutoff }}{ }^{[26} T_{2 \text { cutoff }}$ also is the split point of the micropores and mesopores, and the split point of the mesopores and macropores can be determined by $T_{2 b}=9 T_{2 \text { cutoff }}$. The end point of macropores in $T_{2}$ spectrum can be obtained when the cumulative porosity under $100 \%$ water saturation becomes constant, and $T_{2 n}=734.75 \mathrm{~ms}$. Using this method, the split points on $T_{2}$ spectrum of each core sample were determined, as shown in Table 3 . The absolute porosity of micropores, mesopores and macropores were calculated, as shown in Table 4 . Averagely, micropores occupy nearly $50 \%$ of total pore volume, as the micropore volumes equal the volumes of irreducible water, which indicates that averagely, nearly half of the water is irreducible, and mesopores take up more than one third of pore volumes, but macropores contribute less than $20 \%$ of pore volumes.

\subsection{Fractal Dimension Calculation}

Figure 7 shows the $S_{V}-T_{2}$ curve of core sample 3 in a $\log -\log$ plot. The $S_{V}-T_{2}$ curve is not straight and the slope of $S_{V}-T_{2}$ curve decreases with the

Table 3 The Split Points on NMR $T_{2}$ Spectrum of All the Core Samples.

\begin{tabular}{ccccc}
\hline Sample & $\boldsymbol{T}_{\mathbf{2} \boldsymbol{i}}(\mathbf{m s})$ & $\boldsymbol{T}_{\mathbf{2} \boldsymbol{a}}=\boldsymbol{T}_{\mathbf{2 c u t o f f}}(\mathbf{m s})$ & $\boldsymbol{T}_{\mathbf{2 b}}=\mathbf{9}_{\mathbf{2 c u t o f f}}(\mathbf{m s})$ & $\boldsymbol{T}_{\mathbf{2 n}}(\mathbf{m s})$ \\
\hline 1 & 0.3 & 18.19 & 160.22 & 659.02 \\
2 & 0.3 & 22.61 & 199.16 & 1955.86 \\
3 & 0.3 & 18.19 & 160.22 & 734.75 \\
4 & 0.3 & 3.22 & 28.86 & 258.64 \\
5 & 0.3 & 4.64 & 41.6 & 774.26 \\
6 & 0.3 & 2.23 & 20.03 & 447.5 \\
7 & 0.3 & 3.87 & 34.65 & 310.5 \\
8 & 0.3 & 3.87 & 34.64 & 310.5 \\
9 & 0.3 & 3.87 & 34.65 & 215.44 \\
\hline
\end{tabular}

Table 4 The Absolute Porosity and Porosity Percent of Micropores, Mesopores and Macropores in All the Core Samples.

\begin{tabular}{|c|c|c|c|c|c|c|}
\hline \multirow[t]{2}{*}{ Sample } & \multicolumn{2}{|c|}{ Micropores } & \multicolumn{2}{|c|}{ Mesopores } & \multicolumn{2}{|c|}{ Macropores } \\
\hline & $\begin{array}{c}\text { Absolute } \\
\text { Porosity (\%) }\end{array}$ & $\begin{array}{l}\text { Percent } \\
\quad(\%)\end{array}$ & $\begin{array}{c}\text { Absolute } \\
\text { Porosity (\%) }\end{array}$ & $\begin{array}{l}\text { Percent } \\
(\%)\end{array}$ & $\begin{array}{c}\text { Absolute } \\
\text { Porosity (\%) }\end{array}$ & $\begin{array}{c}\text { Percent } \\
(\%)\end{array}$ \\
\hline 1 & 2.71 & 59.65 & 0.44 & 9.69 & 1.39 & 30.66 \\
\hline 2 & 3.62 & 33.50 & 4.72 & 43.68 & 2.46 & 22.82 \\
\hline 3 & 5.86 & 38.35 & 6.78 & 44.37 & 2.64 & 17.27 \\
\hline 4 & 7.76 & 50.36 & 6.36 & 41.27 & 1.29 & 8.37 \\
\hline 5 & 11.17 & 71.79 & 3.37 & 21.66 & 1.02 & 6.56 \\
\hline 6 & 6.02 & 35.00 & 7.06 & 41.05 & 4.12 & 23.95 \\
\hline 7 & 6.55 & 41.85 & 6.73 & 43.00 & 2.37 & 15.14 \\
\hline 8 & 8.89 & 52.23 & 5.95 & 34.96 & 2.18 & 12.81 \\
\hline 9 & 6.75 & 38.66 & 7.67 & 43.93 & 3.04 & 17.41 \\
\hline Average & 6.59 & 46.82 & 5.45 & 35.96 & 2.28 & 17.22 \\
\hline
\end{tabular}




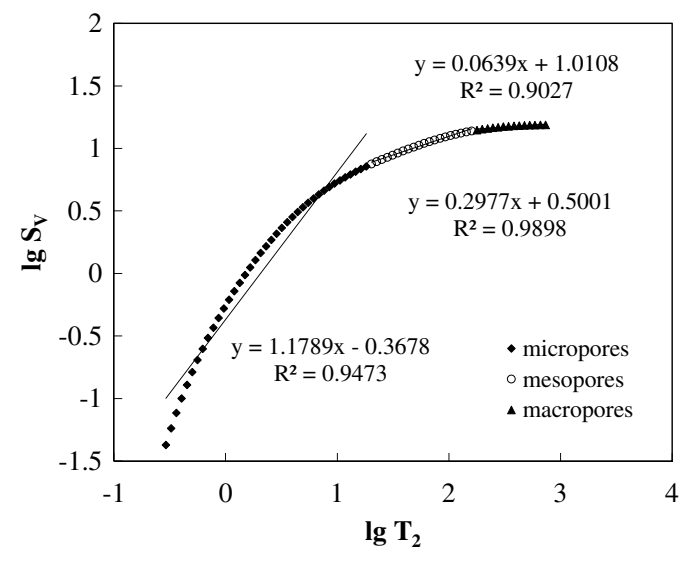

Fig. 7 The $\lg S_{V}-\lg T_{2}$ curves of micropores, mesopores and macropores of core sample 3 .

increasing $T_{2}$. With the split points determined above, the entire $S_{V}-T_{2}$ curve was divided into three segments, which contain the fractal characteristics of micropores, mesopores and macropores, respectively. For each segment, the slope of $S_{V}-$ $T_{2}$ curve can be treated as constant, and a linear regression was applied to obtain the average slope. Then, the fractal dimensions of micropores, mesopores and macropores were calculated. The linear relation and power function relation between $T_{2}$ and pore radius were, respectively, used to calculate fractal dimensions. For the linear relation between $T_{2}$ and pore radius (Eq. (4)), the fractal dimensions were calculated by $D_{f}=3-S$, and the calculated fractal dimensions of micropores, mesopores and macropores were noted as $D_{f 1}, D_{f 2}$ and $D_{f 3}$, respectively. For the power function relation between $T_{2}$ and pore radius (Eq. (9)), the fractal dimensions were calculated by $D_{f}=3-n S$. The calculated fractal dimensions of micropores, mesopores and macropores were noted as $D_{f 1}^{\prime}, D_{f 2}^{\prime}$ and $D_{f 3}^{\prime}$, respectively. The fractal dimension calculation results of all the core samples are shown in Table 5 .

The fractal dimensions calculated using the power function relation between $T_{2}$ and pore radius are greater than those calculated using the linear relation between $T_{2}$ and pore radius. The reason can be explained as follows. As shown in Table 2, the exponents $n$ of power regression for these core samples vary from 0.523 to 0.898 , which are less than 1 . As the slope $S$ is positive, there is $3-n S>$ $3-S$, which means that the fractal dimensions calculated using the power function relation between $T_{2}$ and pore radius are greater. Except core sample 1 , nearly all the micropore fractal dimensions calculated with the linear relation between $T_{2}$ and pore radius are less than 2 . However, the range of fractal dimension in three-dimensional space should be $2<D_{f}<3$. Using the power function relation between $T_{2}$ and pore radius, most of the calculated micropore fractal dimensions are greater than 2 . Considering the bound water occurred in the micropores with large specific surface, micropore fractal dimensions mainly reflect surface fractal characteristics of micropores. ${ }^{24}$ The fractal dimensions of mesopores calculated with the power function relation between $T_{2}$ and pore radius vary between 2.747 and 2.991, and the fractal dimension of macropores are very close to 3 and the differences between each other are very small, in a range of 2.951 to 2.986. Comparing the fractal dimensions of different size pores, the fractal dimensions increase with the pore size increasing from micropores to macropores, which indicates that with pore size increasing from micropores to macropores, pore structures become more complex and heterogeneous.

Table 5 The Calculated Fractal Dimensions of Micropores, Mesopores and Macropores for All the Core Samples.

\begin{tabular}{|c|c|c|c|c|c|c|c|c|c|c|c|c|c|}
\hline \multirow[t]{2}{*}{ Sample } & \multirow[t]{2}{*}{$n$} & \multicolumn{4}{|c|}{ Micropores } & \multicolumn{4}{|c|}{ Mesopores } & \multicolumn{4}{|c|}{ Macropores } \\
\hline & & $S_{1}$ & $R^{2}$ & $D_{f 1}$ & $D_{f 1}^{\prime}$ & $S_{2}$ & $R^{2}$ & $D_{f 2}$ & $D_{f 2}^{\prime}$ & $S_{3}$ & $R^{2}$ & $D_{f 3}$ & $D_{f 3}^{\prime}$ \\
\hline 1 & 0.523 & 0.917 & 0.915 & 2.083 & 2.521 & 0.018 & 0.863 & 2.982 & 2.991 & 0.027 & 0.944 & 2.973 & 2.986 \\
\hline 2 & 0.527 & 1.038 & 0.944 & 1.963 & 2.453 & 0.262 & 0.980 & 2.738 & 2.862 & 0.027 & 0.835 & 2.973 & 2.986 \\
\hline 3 & 0.547 & 1.179 & 0.947 & 1.821 & 2.355 & 0.298 & 0.990 & 2.702 & 2.837 & 0.064 & 0.902 & 2.936 & 2.965 \\
\hline 4 & 0.797 & 1.338 & 0.957 & 1.662 & 1.933 & 0.246 & 0.972 & 2.754 & 2.804 & 0.036 & 0.859 & 2.964 & 2.972 \\
\hline 5 & 0.898 & 1.104 & 0.928 & 1.896 & 2.008 & 0.104 & 0.966 & 2.896 & 2.907 & 0.016 & 0.893 & 2.984 & 2.985 \\
\hline 6 & 0.810 & 1.500 & 0.969 & 1.500 & 1.785 & 0.313 & 0.972 & 2.688 & 2.747 & 0.072 & 0.836 & 2.928 & 2.942 \\
\hline 7 & 0.788 & 1.295 & 0.952 & 1.705 & 1.979 & 0.305 & 0.985 & 2.695 & 2.759 & 0.043 & 0.831 & 2.957 & 2.966 \\
\hline 8 & 0.722 & 1.230 & 0.949 & 1.770 & 2.112 & 0.212 & 0.968 & 2.788 & 2.847 & 0.039 & 0.919 & 2.961 & 2.972 \\
\hline 9 & 0.667 & 1.313 & 0.955 & 1.687 & 2.124 & 0.323 & 0.990 & 2.677 & 2.784 & 0.074 & 0.885 & 2.926 & 2.951 \\
\hline
\end{tabular}




\subsection{Relationships Between Fractal Dimensions and Petrophysical Properties}

The relationships between the fractal dimensions of micropores, mesopores and macropores calculated from NMR $T_{2}$ spectrum and the petrophysical properties of tight oil sandstones were analyzed. Petrophysical properties include air permeability, porosity, reservoir quality index (RQI) and several pore structure parameters derived from MIP, such as pore size and tortuosity. The power function relations between $T_{2}$ and pore size were utilized when fractal dimensions were calculated from NMR $T_{2}$ spectrum. As Fig. [8]shows, the fractal dimensions of mesopores and macropres are strongly correlated with the petrophysical properties, and the correlations between mesopore fractal dimensions and petrophysical properties are stronger, but the correlations between the micropore fractal dimensions and petrophysical properties are weak. It could be concluded that mesopores and macropores have the strongest effects on the petrophysical properties, and although micropores occupy almost the

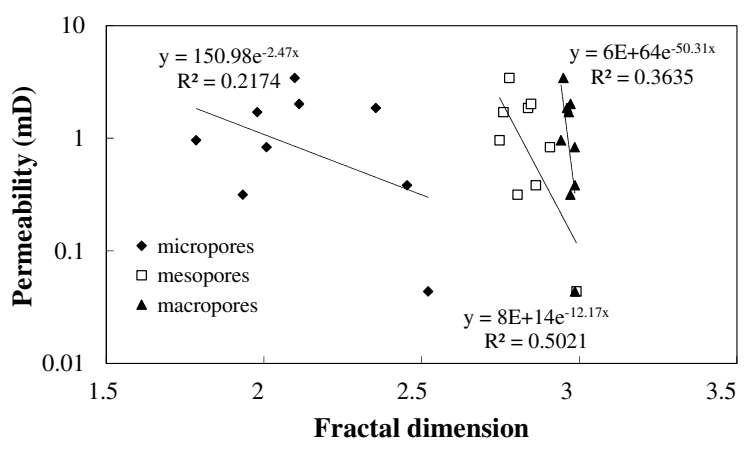

(a)

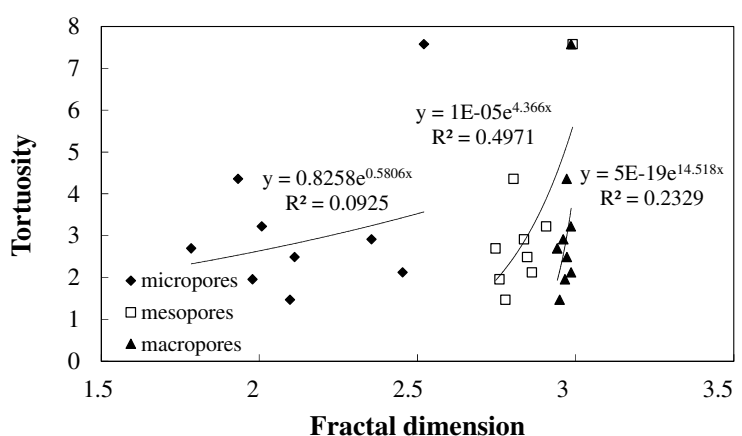

(c)

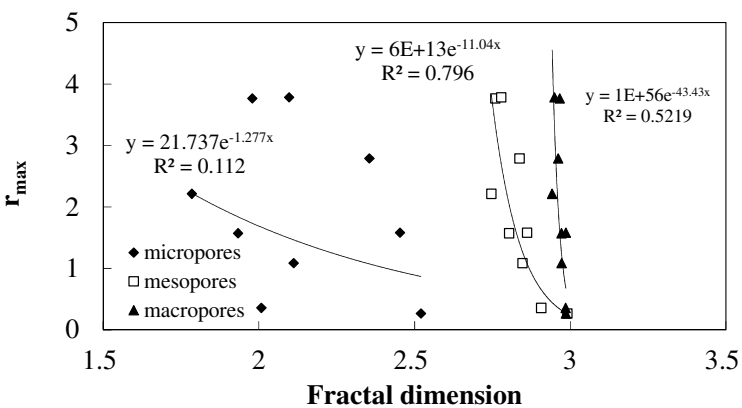

(e)

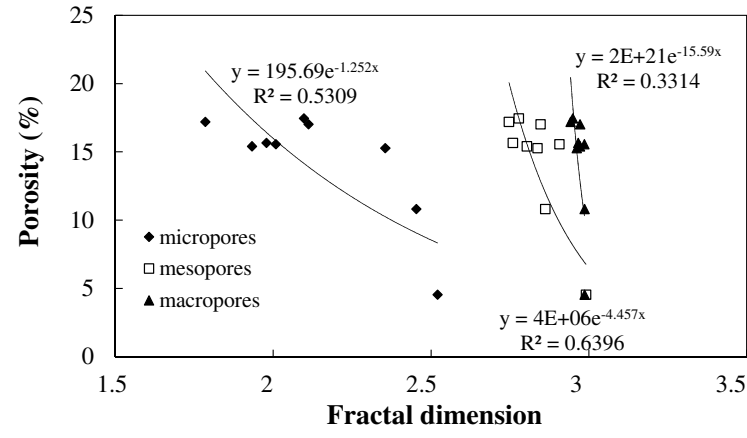

(b)

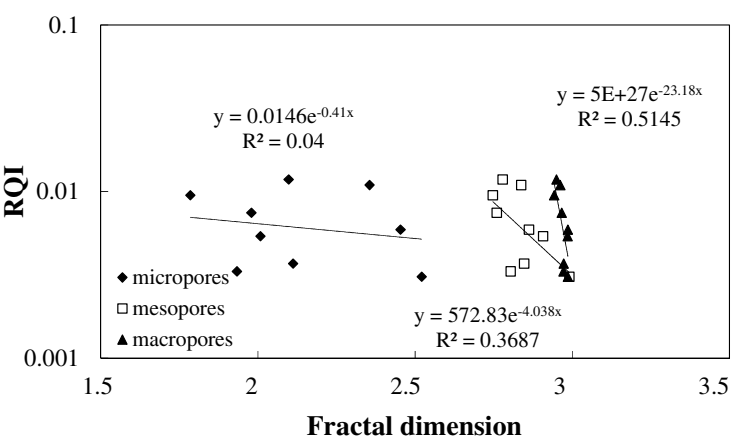

(d)

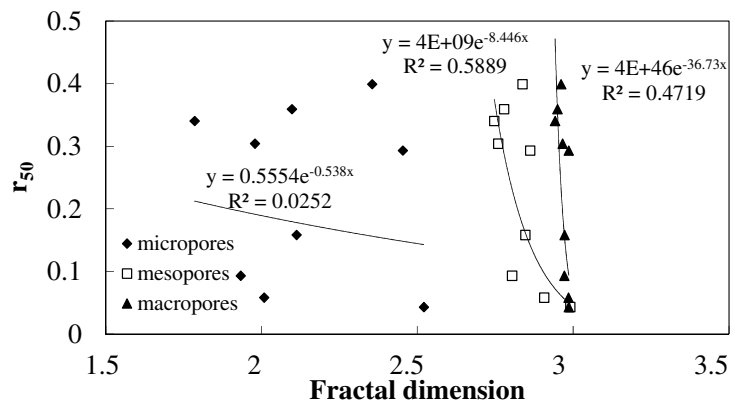

(f)

Fig. 8 The relationships between the fractal dimensions of different size pores calculated from NMR $T_{2}$ spectrum and petrophysical properties of tight oil sandstones ((a) fractal dimensions versus air permeability; (b) fractal dimensions versus porosity; (c) fractal dimensions versus tortuosity; (d) fractal dimensions versus RQI; (e) fractal dimensions versus maximum pore throat radius $r_{\max }$; (f) fractal dimensions versus median pore radius $r_{50}$ ). 
half of pore volumes, petrophysical properties are mainly dominated by mesopores and macropores. With fractal dimensions of mesopores and macropres increasing, the pore throat sizes of core samples decrease exponentially, and air permeability, porosity and RQI decrease significantly, and meanwhile the tortuosity of pore networks increases. Thus, it can be concluded that fractal dimensions of mesopores and macropres calculated from NMR $T_{2}$ spectrum can be used as an effective tool for analyzing petrophysical properties of tight oil sandstones.

\section{CONCLUSIONS}

Pore structures of tight oil sandstones from Yanchang Formation, Ordos Basin of China were characterized with NMR and MIP using fractal theory. The correlation between NMR $T_{2}$ and pore size is more accordant with the power function relation rather than the linear relation. NMR $T_{2}$ spectrum can be divided into three segments corresponding to micropores, mesopores and macropores based on the value of $T_{2 \text { cutoff }}$. With the pore size increasing from micropores to mesopores and macropores, the calculated fractal dimensions from NMR $T_{2}$ spectrum increase and are close to 3 . Petrophysical properties of tight oil sandstones are strongly correlated with fractal dimensions of mesopores and macropores, but have weak correlations with micropore fractal dimensions. With the fractal dimensions of mesopores and macropores increasing, petrophysical properties of tight oil sandstones become poor. The fractal dimension calculated from NMR $T_{2}$ spectrum can be applied as an effective tool for analyzing petrophysical properties of tight oil sandstone reservoirs.

\section{ACKNOWLEDGMENTS}

This work was supported by the National Natural Science Foundation of China (Nos. 51604285 and 41722403), Beijing Municipal Natural Science Foundation (No. 3164048) and Scientific Research Foundation of China University of Petroleum, Beijing (Nos. 2462017BJB11 and 2462016YQ1101).

\section{REFERENCES}

1. H. Gao and H. A. Li, Pore structure characterization, permeability evaluation and enhanced gas recovery techniques of tight gas sandstones, J. Nat. Gas Sci. Eng. 28 (2016) 536-547.
2. W. Wang, D. Zheng, G. Sheng, Q. Zhang and Y. $\mathrm{Su}$, A review of stimulated reservoir volume characterization for multiple fractured horizontal well in unconventional reservoirs, Adv. Geo-Energ. Res. 1(1) (2017) 54-63.

3. G. Desbois, J. L. Urai, P. A. Kukla, J. Konstanty and C. Baerle, High-resolution 3D fabric and porosity model in a tight gas sandstone reservoir: A new approach to investigate microstructures from mmto nm-scale combining argon beam cross-sectioning and SEM imaging, J. Petrol. Sci. Eng. 78(2) (2011) 243-257.

4. K. Xi, Y. Cao, B. G. Haile, R. Zhu, J. Jahren, K. Bjørlykke, X. Zhang and H. Hellevang, How does the pore-throat size control the reservoir quality and oiliness of tight sandstones? The case of the Lower Cretaceous Quantou Formation in the southern Songliao Basin, China, Mar. Petrol. Geol. 76 (2016) $1-15$.

5. B. B. Mandelbrot and R. Pignoni, The Fractal Geometry of Nature (W.H. Freeman, New York, 1983).

6. B. Yu and P. Cheng, A fractal permeability model for bi-dispersed porous media, Int. J. Heat. Mass Transf. 45(14) (2002) 2983-2993.

7. M. Yun, B. Yu and J. Cai, Analysis of seepage characters in fractal porous media, Int. J. Heat Mass Transf. 52(13-14) (2009) 3272-3278.

8. C. Zou, R. Zhu, K. Liu, L. Su, B. Bai, X. Zhang, X. Yuan and J. Wang, Tight gas sandstone reservoirs in China: Characteristics and recognition criteria, J. Petrol. Sci. Eng. 88-89 (2012) 82-91.

9. F. Wang, P. Lian, L. Jiao, Z. Liu, J. Zhao and J. Gao, Fractal analysis of microscale and nanoscale pore structures in carbonates using high-pressure mercury intrusion, Geofluids (2018) (in press).

10. J. Cai, W. Wei, X. Hu, R. Liu and J. Wang, Fractal characterization of dynamic fracture network extension in porous media, Fractals 25 (2017) 17500232.

11. K. Li, Analytical derivation of Brooks-Corey type capillary pressure models using fractal geometry and evaluation of rock heterogeneity, J. Petrol. Sci. Eng. 73(1-2) (2010) 20-26.

12. J. Lai and G. Wang, Fractal analysis of tight gas sandstones using high-pressure mercury intrusion techniques, J. Nat. Gas Sci. Eng. 24 (2015) 185196.

13. B. Bin, Z. Rukai, W. Songtao, Y. Wenjing, J. Gelb, A. Gu, X. Zhang and S. U. Ling, Multi-scale method of Nano (Micro)-CT study on microscopic pore structure of tight sandstone of Yanchang formation, Ordos Basin, Petrol. Explor. Dev. 40(3) (2013) 354358.

14. E. Vergés, D. Tost, D. Ayala, E. Ramos and S. Grau, 3D pore analysis of sedimentary rocks, Sediment. Geol. 234(1-4) (2011) 109-115. 
15. Y. Zhao, G. Zhu, Y. Dong, N. N. Danesh, Z. Chen and T. Zhang, Comparison of low-field NMR and microfocus X-ray computed tomography in fractal characterization of pores in artificial cores, Fuel $\mathbf{2 1 0}$ (2017) 217-226.

16. Z. Cao, G. Liu, H. Zhan, C. Li, Y. You, C. Yang and H. Jiang, Pore structure characterization of Chang-7 tight sandstone using MICP combined with N2GA techniques and its geological control factors, Sci. Rep. 6 (2016) 36919.

17. C. N. Zou, Z. Yang, S. Z. Tao, X. J. Yuan, R. K. Zhu, L. H. Hou, S. T. Wu, L. Sun, G. S. Zhang and B. Bai, Continuous hydrocarbon accumulation over a large area as a distinguishing characteristic of unconventional petroleum: The Ordos Basin, NorthCentral China, Earth-Sci. Rev. 126 (2013) 358-369.

18. J. Doveton and L. Watney, Textural and pore size analysis of carbonates from integrated core and nuclear magnetic resonance logging: An Arbuckle study, Interpretation 3(1) (2014) SA77-SA89.

19. R. Rezaee, A. Saeedi and B. Clennell, Tight gas sands permeability estimation from mercury injection capillary pressure and nuclear magnetic resonance data, J. Petrol. Sci. Eng. 88-89 (2012) 92-99.

20. X. Shao, X. Pang, H. Li and X. Zhang, Fractal analysis of pore network in tight gas sandstones using NMR method: A case study from the Ordos basin, China, Energ. Fuel 31(10) (2017) 10358-10368.

21. Y. Yao, D. Liu, Y. Che, D. Tang, S. Tang and W. Huang, Petrophysical characterization of coals by low-field nuclear magnetic resonance (NMR), Fuel 89(7) (2010) 1371-1380.

22. Y. Yao and D. Liu, Comparison of low-field NMR and mercury intrusion porosimetry in characterizing pore size distributions of coals, Fuel 95(1) (2012) $152-158$.

23. X. Ge, Y. Fan, X. Zhu, Y. Chen and R. Li, Determination of nuclear magnetic resonance T2 cutoff value based on multifractal theory - An application in sandstone with complex pore structure, Geophysics 80(1) (2015) D11-D21.

24. Z. Zhang and A. Weller, Fractal dimension of porespace geometry of an Eocene sandstone formation, Geophysics 79(6) (2014) D377-D387.

25. Q. Chang, The study of microscopic pore structures and percolation characteristics of low permeability formation in Yanchang oilfield, Master thesis, China University of Petroleum, Beijing (2014).

26. H. Gao and H. Li, Determination of movable fluid percentage and movable fluid porosity in ultra-low permeability sandstone using nuclear magnetic resonance (NMR) technique, J. Petrol. Sci. Eng. 133 (2015) 258-267.

27. E. W. Washburn, The dynamics of capillary flow, Phys. Rev. 17(3) (1921) 273.

28. G. R. Coates, L. Xiao and M. G. Prammer, NMR Logging: Principles and Applications (Haliburton Energy Services, Houston, 1999).

29. H. Daigle and A. Johnson, Combining mercury intrusion and nuclear magnetic resonance measurements using percolation theory, Transp. Porous Media 111(3) (2016) 669-679.

30. L. Xiao, Z. Mao, C. Zou, Y. Jin and J. Zhu, A new methodology of constructing pseudo capillary pressure $(\mathrm{Pc})$ curves from nuclear magnetic resonance (NMR) logs, J. Petrol. Sci. Eng. 147 (2016) 154167.

31. W. F. Slijkerman, J. P. Hofman, W. J. Looyestijn and Y. Volokitin, A practical approach to obtain primary drainage capillary pressure curves from NMR core and log data, Petrophysics 42(4) (2001) 334343.

32. A. Li, X. Ren, G. Wang, Y. Wang and K. Jiang, Characterization of pore structure of low permeability reservoirs using a nuclear magnetic resonance method, J. China Univ. Petrol. 6(39) (2015) 92-98. 